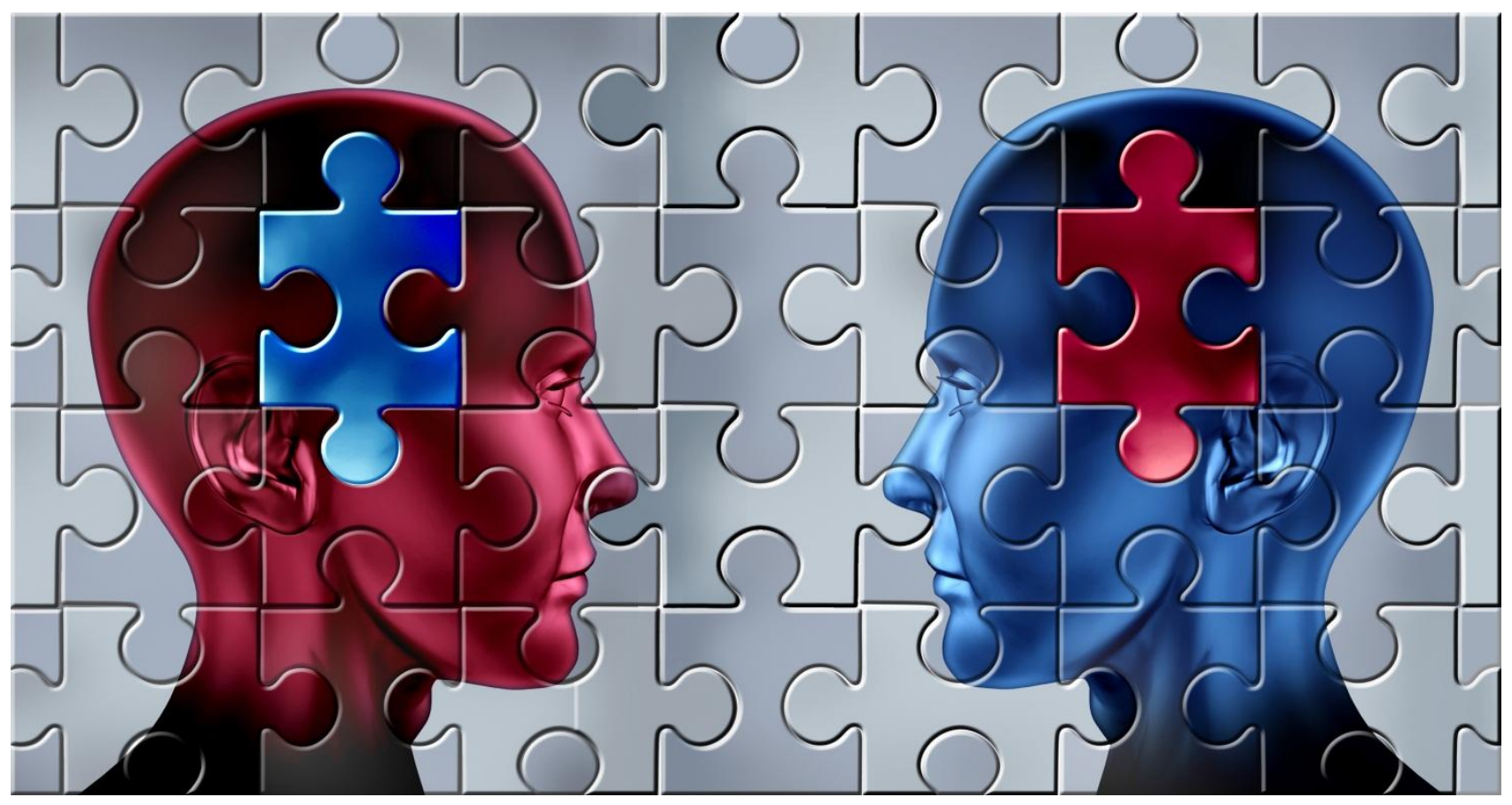

Exchanges: the Warwick Research Journal

Volume 2 (1), October 2014

http:/ / exchanges.warwick.ac.uk

Four key reasons why

climate change adaptation and mitigation need a gendered approach

Carla Sarrouy 


\title{
Four key reasons why climate change adaptation and mitigation need a gendered approach
}

\author{
Carla Sarrouy (University of Warwick)
}

\begin{abstract}
Climate change is having a growing impact on every human activity, especially on agriculture with altered rainfall patterns and an increased number and intensity of extreme weather events. This article argues that efforts to mitigate and adapt to climate change must consider whole food systems - rather than the sole production of foodwhilst embracing a conscious gendered approach. Women are the main victims of hunger, but they are also the main actors of global food systems, they greatly contribute to their household's and community's wellbeing and detain a rich and often untapped knowledge of food systems. Promoting the role of women in our global food systems enhances the inclusion of criteria mainly valued by women such as resilience, diversity and nutrition, which are paramount for climate change mitigation and adaptation.
\end{abstract}

Keywords: climate change, gender, food systems, agriculture, adaptation.

The Intergovernmental Panel on Climate Change report (IPCC, 2014) published earlier this year sheds little new light on the issue of climate change but rather reinstates with added authority previous key conclusions: climate change is happening, it is mainly anthropogenic, and it requires urgent action.

Human activities, such as mass deforestation and mining, have greatly contributed to changes in the climate in a global scale and might compromise our very own sustainable development. Senegal's dependency on peanut production for export is a blatant example of an unsustainable food system, highly affected by climate change, which is bringing the nation to its knees. As increases in heat and decreases in rainfall make it harder to produce peanuts, the main cash crop for export (environmental pillar) (Herrmann and Tappan, 2013), the lack of revenue from selling cash crops means that households need to survive on less income (economic pillar) (Demont et al., 2013) and environmental degradation and lower incomes end up deteriorating people's nutritional and food security (social pillar) (Rioux et al., 2011). Senegal's example of how climate 
change is further challenging its unsustainable food system is far from being unique in the world. At the global scale, although climate change is often perceived as a catastrophic call, it is also a call of opportunity, an alarm bell that tolls to make humankind think of its impact on the Earth.

Agriculture is considered to be the second biggest source of greenhouse gas emissions in the world, mainly nitrous oxide from fertiliser production, methane from irrigation and livestock production and carbon dioxide from energy use for fuel and heating (Herzog, 2009). Efforts to abate (mitigate) and to adapt to climate change need to be undertaken urgently and simultaneously. Present mitigation efforts will only bear fruit in the future due to the inertia of the climate system; however, adaptation efforts can be undertaken now with immediate effects. Adaptation efforts need to go beyond agriculture and the mere production of food; adaptation efforts need to embrace a food systems approach, involving every stage from food production to food consumption and disposal and including all stakeholders (farmers, processors, retailers, consumers, etc.). Moreover, all efforts in both mitigation and adaptation to climate change need to adopt a gendered approach $^{1}$ of world food systems, for four crucial reasons that cannot be underestimated:

\section{Women are the main victims of hunger}

The United Nations Food and Agriculture Organisation (FAO, 2013) estimated that, although the world is producing enough to feed its 7.1 billion inhabitants, approximately one in eight people still go to bed hungry every day. Of these 870 million undernourished people, 60\% are women and girls (HLPE, 2012). This gender inequality in food is ever more concerning due to the way the vicious cycle of undernutrition operates: an undernourished mother gives birth to an undernourished child, who will have higher morbidity and lower chances of surviving its first 5 years of life (The Lancet, 2013). In turn, if the child is a girl and succeeds in achieving teen-age, she will have higher probability of giving birth to an undernourished child and thus pursuing the cycle of chronic undernutrition (Troubé, 2007). Efforts to adapt to climate change and

\footnotetext{
${ }^{1}$ As opposed to 'sex' which refers to the innate and fixed biological categories of male and female, 'gender' refers to the sociological conceptions of what it means to be a man or a woman. Gender roles and perceptions change in time and space and are influenced by religion, culture, ideologies and ethnicities.
} 
fight hunger via improved agriculture and world food systems must undoubtedly include women. According to The Lancet (2013),

[t]argeted agricultural programmes have an important role in support of livelihoods, food security, diet quality, and women's empowerment, and complement global efforts to stimulate agricultural productivity and thus increase producer incomes while protecting consumers from high food prices. (...) Evidence suggests that targeted agricultural programmes are more successful when they incorporate strong behaviour change communications strategies and a gender-equity focus.

\section{Women are the main actors of global food systems}

Women are key players in agriculture and according to the World Bank's Gender in Agriculture Sourcebook (2009), women account for $60-80 \%$ of total food production in developing countries.

Women are involved in sowing, weeding, applying fertiliser and pesticides, and harvesting and threshing of crops. Moreover, in many countries they are responsible for the household's legumes and vegetables and participate in the livestock sector, feeding and milking larger animals and raising poultry and small animals, such as goats, guinea pigs, rabbits, and sheep. Furthermore, rural women provide most postharvest labour, arrange storage, and take care of handling, stocking, processing, and marketing of the produce. (World Bank 2009)

Women's role extends beyond food production; they have the so-called 'triple-burden' of being responsible for household nutrition (growing and preparing food), but also child rearing and often market selling of the produce. According to De Schutter (2012), 'this "care economy" for which [women] remain chiefly responsible results in time poverty for women. Women work more hours than men, although much of the work they perform remains informal, essentially performed within the family, and unremunerated, and this is neither valued nor even recognized'. These different tasks require flexibility and adaptability from women, two skills that are already being put into use in their approach to food production. Given the same resources, women are as productive in 
agriculture as men, however in reality women have less access to resources (such as land, livestock and technology) so they end up producing less. If this gender gap was closed, there would be a major increase in agricultural productivity in the world (including 10-20\% in sub-Saharan Africa) thus contributing to increase the food security of many households (FAO, 2011).

\section{Women spread the wealth}

Investing in women has the double benefit of improving their own lives and the lives of their households. As an example, improving the nutrition of a young woman increases her chances of giving birth to a well-nourished baby, which could potentially be breastfed and benefit from a healthy diet during its early development (Black et al., 2013). Similarly, educating a mother will have a bigger correlated impact on the education of her children than educating the father (Cooray and Potrafke, 2011). Finally, the financial empowerment of women also benefits greatly the overall household as according to research conducted by Hoddinott and Haddad (1995) and cited by the FAO Committee on Food Security (2011), increasing a woman's income by $\$ 10$ achieves the same improvements in children's nutrition and health as increasing a man's income by $\$ 110$. This is due to the fact that women, compared to men, spend a higher proportion of their income on food and education for the family and less on items such as alcohol and cigarettes (Hoddinott and Haddad, 1995). The understated importance of the 'humancapital transmission through mothers' (Cooray and Potrafke, 2011) has the potential to break the inversed cycles of undernourishment and poverty which have been plaguing countless families for generations.

\section{Women have untapped knowledge of sustainable food systems}

Due to their role in food systems, women have a more all-encompassing approach to ensuring there is appropriate food for all household members (food security) and deciding the functioning of their food system (food sovereignty). Women are often responsible for food crops, i.e. crops that are grown to feed the family and, because of their lack of resources, female farmers adopt very diverse and complementary agricultural methods that make the most of their little (and often poor) land (FAO, 2011; 
Pionetti, 2005). The very high diversity of crops in their plots reduces the risk of having no food at all due to climate variability and ensures their environmental resilience. Moreover, women promote social resilience when growing foods with all aspects of agricultural work, food preparation and nutrition in mind and not solely the unsustainable obsession with yields. In this sense, female smallholders adopt an approach that is closer to what Olivier de Schutter (2010), the former UN Rapporteur on the right to food refers to as agroecology, as it embraces a holistic approach that considers food systems, rather than simply agriculture. Female farmers' deep knowledge of crops, land, nutrition, climate and farming efficiency, is key for climate change adaptation and mitigation (IAASTD, 2009).

In spite of these facts, there is still a relatively scarce body of research and policy influence that gives its right weight and value to the role of women in food systems and climate change adaptation. Most research remains gender-blind, thus favouring the status quo of the most powerful, mainly men. Lessons need to be learnt from the Green Revolution, an initiative, promoted by public and private actors, which started in the 1960s with the aim of improving agricultural yields thanks to the development and introduction of high-yielding varieties (HYV) of selected crops and by delivering loans, HYV seeds and chemical inputs to farmers in poor, hunger-stricken developing countries (Conway, 1997; Rockefeller Foundation, 2013). The Green Revolution managed to increase yields for certain crops in certain areas of the globe (Evenson and Gollin, 2003) but with complete disregard for environmental and nutritional concerns (Patel, 2012). Most smallholders, mainly women, were left behind and have continued to practice a more traditional, diversified and holistic agriculture with the primary goal of feeding their families rather than joining the commodities market (Holt-Giménez and Altieri, 2012).

Climate change predictions foresee an increase in global mean temperature and in extreme weather events such as floods and droughts. The unpredictability and apparent dichotomy of these events begs for an agriculture - and indeed food systems - that are highly resilient. Diversity, rather than over-specialisation, serves as an insurance scheme for farmers, enabling them to be both environmentally and socially resilient by ensuring that (at least part of) their crops will grow and supply a nutritious diet to all members of 
the household. Food systems of the future, adapted to climate change, needs to further embrace criteria valued by female smallholders, understanding that the nutrition of food is paramount and that disrespecting the environment and its natural cycles leads to illness and self-destruction.

Limited by their smaller access to resources, women traditionally invest in highly resilient, flexible and holistic food systems. So whilst the political sphere is debating the importance and extent of climate change and trying to work on an almost-impossible long-term scale so counter-intuitive to modern day policy making; adaptation is already happening in the fields with the promotion of integrated approaches to make food systems more resilient. High-tech developments to increase agricultural production, such as the Green Revolution or new developments such as genetically modified organisms, remain in the hands of the few, for the few and often constitute sources of environmental degradation and economic dependency (Glover, 2008; Holt-Gimenez et al., 2006; IAASTD, 2009). These technocratic approaches may seem very tempting for policy makers, but so far they have often proved to only be a 'fuite en avant', a delaying of the inevitable reconciliation with nature's terms and conditions. Climate change is happening; it requires urgent action, a holistic approach to our food systems and, therefore, the acknowledgement of the key role that women play in them.

\section{References}

Black, R.E., Victora, C.G., Walker, S.P., Bhutta, Z.A., Christian, P., de Onis, M., Ezzati, M., Grantham-McGregor, S., Katz, J., Martorell, R., Uauy, R., 2013. Maternal and child undernutrition and overweight in low-income and middle-income countries. The Lancet 382, 427-451.

Conway, G., 1997. The Doubly Green Revolution: Food for All in the Twenty-First Century, Penguin Books Ltd., London, UK.

Cooray, A., Potrafke, N., 2011. Gender inequality in education: Political institutions or culture and religion? European Journal of Political Economy 27, 268-280.

De Schutter, O., 2010. Agroecology and the right to food. United Nations, New York.

De Schutter, O., 2012. Women's rights and the right to food. United Nations, New York. 
Demont, M., Rutsaert, P., Ndour, M., Verbeke, W., 2013. Reversing Urban Bias in African Rice Markets: Evidence from Senegal. World Development 45, 63-74.

Evenson, R.E., Gollin, D., 2003. Assessing the Impact of the Green Revolution, 1960 to 2000. Science 300, 758-762.

FAO, 2011. The State of Food and Agriculture. Women in Agriculture - closing the gender gap for development. FAO, Rome.

FAO, 2013. FAO stat, Rome.

FAO CFS, 2011. Policy Roundtable: Gender, Food Security and Nutrition, UN Food and Agriculture Organisation Committee on World Food Security, Rome.

Glover, D., 2008. Made by Monsanto: the Corporate Shaping of GM Crops as a Technology for the Poor. STEPS Centre, Brighton, UK.

Herrmann, S.M., Tappan, G.G., 2013. Vegetation impoverishment despite greening: A case study from central Senegal. Journal of Arid Environments 90, 55-66.

Herzog, T., 2009. World Greenhouse Gas Emissions in 2005 - Working Paper. World Resources Institute.

HLPE, 2012. Climate change and food security. A report by the High Level Panel of Experts on Food Security and Nutrition of the Committee on World Food Security. HLPE, Rome.

Hoddinott, J., Haddad, L., 1995. Does Female Income Share Influence Household Expenditures? Evidence from Cote d'Ivoire. Oxford Bulletin of Economics and Statistics 57, 77-96.

Holt-Gimenez, E., Altieri, M., Rosset, P.M., 2006. Food First Policy Brief No. 12: Ten Reasons Why the Rockefeller and the Bill and Melinda Gates Foundations' Alliance for Another Green Revolution Will Not Solve the Problems of Poverty and Hunger in Sub-Saharan Africa. Institute of Food and Development Policy, Oakland.

Holt-Giménez, E., Altieri, M.A., 2012. Agroecology, Food Sovereignty, and the New Green Revolution. Agroecology and Sustainable Food Systems 37, 90-102. 
IAASTD, 2009. Agriculture at a Crossroads. A synthesis of the Global and Sub-Global IAASTD Reports. International Assessment of Agricultural Knowledge, Science and Technology for Development (IAASTD), Washington, DC.

IPCC, 2014. Climate Change 2014: Impacts, Adaptation, and Vulnerability. Contribution of Working Group II to the Fifth Assessment Report of the IPCC [Field, C., V. Barros, K. Mach and M. Mastrandrea (eds.)]. Cambridge University Press, Cambridge, UK and New York, NY, USA.

Patel, R., 2012. The Long Green Revolution. The Journal of Peasant Studies 40, 1-63.

Pionetti, C., 2005. Sowing Autonomy: gender and seed politics in semi-arid India. International Institute for Environment and Development (IIED), London, UK.

Rioux, J., Ganli, A., Amouzou, K., Ndiaye, G., Geniez, P., Perenze, L., 2011. Analyse Globale de la Vulnérabilité, de la Sécurité Alimentaire et de la Nutrition (AGVSAN) - Données primaires collectées entre Avril et Juin 2010 - République du Sénégal 2010. Gouvernement du Sénégal, FAO, Unicef, Programme Alimentaire Mondial, Banque Mondiale, Coopération Luxembourgeoise, Fondation Bill \& Melinda Gates, Fonds Espagnols pour les OMD, USAID, Rome.

Rockefeller Foundation, 2013. Strengthening Food Security: Alliance for a Green Revolution in Africa (AGRA).

The Lancet, 2013. Maternal and Child Nutrition - Executive Summary, London, UK.

Troubé, C., 2007. Les nouvelles famines - des catastrophes pas si naturelles. Editions Autrement, Paris.

World Bank, 2009. Gender in Agriculture Sourcebook. World Bank, Washington, DC. 